\title{
Thermal dissociation of sulfur species: Analyzing variations in corrosivity of different condensate feedstock
}

Mabruk I. Suleiman, Mohammad A. Rakib*, Hala Kelani, Mustafa Karakaya, Mohamed Al Musharfy, Abraham George, and Nilesh Chandak

ADNOC Refining Research Centre, PO Box 3593, Abu Dhabi, UAE

Received: 12 February 2018 / Accepted: 9 October 2018

\begin{abstract}
Traditionally, total sulfur content of a crude or condensate feedstock introduced to atmospheric distillation units in a refinery has been used as a measure to predict the high temperature corrosivity of these feeds. Such predictions were also utilized to decide on selection of materials of construction for refinery facilities processing condensate, and many chronic problems, sometimes leading to failure of materials have been reported. In reality, in addition to the total sulfur content, it is important to conduct a profiling of the distribution of the various types of sulfur components in the condensate or crude oil. A pilot plant, mimicking the thermal conditions in a condensate preheat train, was utilized to generate trends of $\mathrm{H}_{2} \mathrm{~S}$ generation under various process conditions. The experimental variables included temperature, pressure, condensate feed rates, and sweep gas flow rates. Yields of $\mathrm{H}_{2} \mathrm{~S}$ generation for the different conditions have been trended for the parametric studies. Such trends were compared for two different condensate feedstock, as a fundamental step towards understanding why different condensate feedstock exhibit significantly different pattern of $\mathrm{H}_{2} \mathrm{~S}$ generation, and hence different corrosivity under similar high temperature processing conditions. Chromatograms of all sulfur containing species, as well as key types of sulfur-containing species have been presented to demonstrate why the $\mathrm{H}_{2} \mathrm{~S}$ yield patterns can vary among different condensates.
\end{abstract}

\section{Introduction}

Condensates are relatively lighter than crude oil and are produced by separation from either crude oil or natural gas, after being released from the production well. The term condensate refers broadly to any type of oil that "condenses" into a liquid after being released from high-pressure wells, where it pre-exists in gas form, or is physically separated from the gas. It has a low-density, high API gravity typically in the range of 50-80 degrees, and Reid Vapor Pressure (RVP) ranging from 2 to 14 psig [1]. In a typical oil refinery, crude oil or condensate streams are first heated in a preheat train and introduced to a distillation unit, where the crude/condensate is separated into several straight run fractions based on the boiling point ranges. A crude/condensate distillation unit is the most energyconsuming unit in the refinery, and also the most vulnerable to corrosion due to the highest concentration of corrosive species in the process streams.

Figure 1 depicts a schematic of a typical condensate distillation unit. Condensate feedstock, which can be from a single origin, or a blend of several condensate feedstock, is first heated up, recovering heat from several product

\footnotetext{
* Corresponding author: mrakib@adnoc.ae
}

pump-around streams in a preheat train consisting of several shell and tube heat exchangers, before being introduced to a preflash column followed by the main fractionator. Table 1 lists typical process conditions of specific streams with numberings as indicated in Figure 1. Depending on the relative tendencies of generating $\mathrm{H}_{2} \mathrm{~S}$ under the operating temperatures of a condensate processing unit, varying degrees of corrosion have been reported, typically the overhead section being the most severely affected zone.

Corrosion of transfer pipelines and process equipment is one of the biggest problems faced by the oil and gas industry, especially in refineries [2-4], and can severely impact safety and integrity of the processing installations, leading to serious accidents. Several types of mitigating safeguards and measures are implemented to minimize corrosion to improve life of installations and reliability of the operations, thereby preventing costly maintenance requirements and operational shutdowns [3-6]. It has been known for very long that high temperature sulfidic corrosion is the main mechanism responsible for the corrosive deterioration of refinery equipment, especially crude distillation and condensate processing circuits [7]. This is primarily attributed to release of $\mathrm{H}_{2} \mathrm{~S}$ into the process stream by the decomposition of active sulfur-containing compounds under the operating conditions endured by the hydrocarbon feed [3, 8, 9]. 


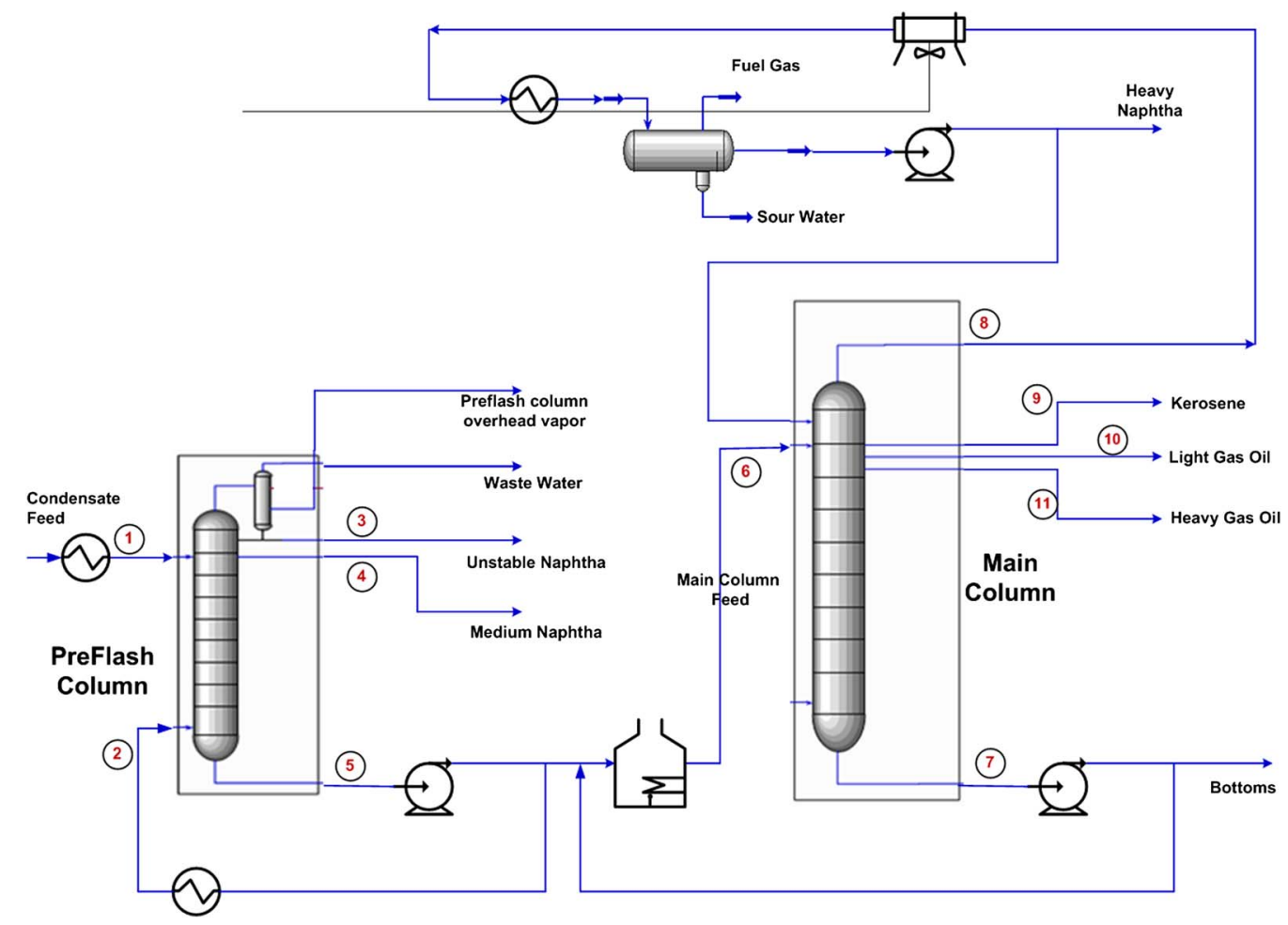

Fig. 1. A schematic diagram of a typical condensate distillation unit.

Table 1. Typical stream temperatures and pressures in a condensate distillation unit.

\begin{tabular}{lcc}
\hline Stream \# & Temperature $\left({ }^{\circ} \mathrm{C}\right)$ & Pressure $\left(\mathrm{kg} / \mathrm{cm}^{2} \mathrm{~g}\right)$ \\
\hline 1 & 180 & 4.3 \\
2 & 265 & 4.25 \\
3 & 90 & 4.25 \\
4 & 155 & 4.95 \\
5 & 230 & 4.7 \\
6 & 315 & 1.05 \\
7 & 300 & 1.1 \\
8 & 125 & 0.7 \\
9 & 185 & 0.88 \\
10 & 295 & 0.92 \\
11 & 345 & 1.02 \\
\hline
\end{tabular}

In refinery processes, the released $\mathrm{H}_{2} \mathrm{~S}$ is recovered from the overhead streams of separation columns by appropriate sour gas treatment methods, descriptions of which can be found elsewhere. Other aspects contributing to the corrosivity of crude oil and condensates include naphthenic acids corrosion [10-16]. In general, refinery feedstock with a Total Acid Number (TAN) greater than $0.3-0.5$ can be potentially corrosive due the presence of naphthenic acids. It has also been reported that formation of a sulfide layer diminishes naphthenic acid corrosion, whereas in general, naphthenic acid corrosion enhances sulfidic corrosion.
Combined effects of naphthenic acid and sulfur species in corrosion of oil and gas systems have been reported elsewhere $[14,17,18]$.

Crude oils with sulfur content greater than $0.2 \mathrm{wt} \%$ have in general been considered to be corrosive for carbon steel as well as to low alloy steels under refinery operating conditions $[2,8]$. As such, sulfur content levels also contribute significantly to the pricing of refinery feedstocks. Refinery pipelines with hot streams, especially heater tubes have been found to suffer from wall corrosion failures, with corrosion rates as high as $1 \mathrm{~mm}$ per year. However, measured corrosion rates of carbon, low alloy, and stainless steels are significantly higher than that predicted by the modified McConomy curves $[3,9,19]$ in cases where significant concentrations of mercaptans are present in crude oils and hydrocarbon condensates. It has been suggested [2, 9, 20] that the controlling factor in sulfidic corrosion is not the total sulfur content of the feedstock, but rather the concentration of particular organic sulfur species, e.g. sulfides, disulfides, mercaptans and thiophenes. The extent to which these sulfur species thermally decompose to form the more corrosive constituents such as $\mathrm{H}_{2} \mathrm{~S}$ determines the severity of sulfidic corrosion $[8,21]$.

High temperature sulfidic corrosion has been reported in refinery processing units, especially at temperatures exceeding $260{ }^{\circ} \mathrm{C}$ [22]. It is generally agreed that this is facilitated by the material of the pipelines and vessels, usually carbon steel, being directly attacked by $\mathrm{H}_{2} \mathrm{~S}$, resulting to the formation of a sulfidic layer.

$$
\mathrm{Fe}+\mathrm{H}_{2} \mathrm{~S} \rightarrow \mathrm{FeS}+\mathrm{H}_{2}
$$


Usually, the FeS layer formed also acts as a protective layer against further corrosion, but in the presence of naphthenic acids, this FeS layer stability is affected, especially under high velocity of fluids in the vicinity [10] and leads further to the formation of another protective layer of iron oxide, more specifically, magnetite.

Naphthenic acid corrosion in the presence of hydrogen sulfide can be represented as [2]:

$$
\begin{gathered}
\mathrm{Fe}+\mathrm{RCOOH} \rightarrow \mathrm{Fe}(\mathrm{RCOO})_{2}+\mathrm{H}_{2} \\
\mathrm{Fe}(\mathrm{RCOO})_{2}+\mathrm{H}_{2} \mathrm{~S} \rightarrow \mathrm{FeS}+2 \mathrm{RCOOH}
\end{gathered}
$$

Equation (2) describes the interaction of organic acids with iron, resulting in the formation of iron-acid complexes that are oil soluble. Equation (1) describes the interaction of hydrogen sulfide with iron, producing iron sulfides. As iron sulfides tend to be oil insoluble, they can form films on the metal and under low shear conditions can protect the metal surface from further corrosion. Finally, equation (3) describes the interaction of hydrogen sulfide with ironorganic acid complexes where the acid is regenerated and iron sulfides are formed.

$\mathrm{H}_{2} \mathrm{~S}$, formed due to thermal decomposition of the active organic sulfur species at temperatures as low as $60{ }^{\circ} \mathrm{C}$, leads the way to metal deterioration at higher temperatures. Concentrations of these sulfur species vary from one feedstock to another [23, 24], and have different decomposition temperature ranges $[7,25,26]$. Several condensate and crude feedstock were studied in laboratory and pilot plant setups $[27,28]$ under controlled conditions for their tendency to produce $\mathrm{H}_{2} \mathrm{~S}$ during thermal decomposition and the resulting corrosion rates were reported. However, these tests did not include complete range of actual process operating conditions in the condensate distillation unit circuit.

Corrosivity of a crude or condensate feedstock has been extensively determined in laboratories subjecting test coupons of different types of materials under varieties of operating conditions [10, 15, 27-29]. In many instances, synthetic or mineral oil was used as the matrix liquid, doped with known concentrations of selected sulfur-containing compounds or naphthenic acids, or both $[10,11,14,17$, 30]. Researchers have also provided experimental data for the decomposition of model sulfur-containing components to generate $\mathrm{H}_{2} \mathrm{~S}$ [26, 31-34]. The use of model sulfur compounds facilitates easier interpretation and correlation of $\mathrm{H}_{2} \mathrm{~S}$ generation. However, prediction of corrosivity tendencies by dissociation model of model components to corrosivity of a real crude or condensate feedstock would be extremely difficult in the absence of detailed sulfur component analysis and their distribution in real feedstock. Others have used crude oil or condensates from different sources around the world to test their corrosivity using coupons made of selected materials [27, 28]. This approach, however, would provide corrosivity predictions only for the crude or condensate samples tested. Studies also involved placing corrosion coupons in several locations of interest in live refinery streams, and analyzing these after removal during refinery shutdown $[35,36]$. In this case, attributing the corrosivity to specific process conditions would not be conclusive, since the stream conditions would have varied
Table 2. Properties of condensate feedstock tested.

\begin{tabular}{lcc}
\hline & TR1 & TR2 \\
\hline Density @ $15{ }^{\circ} \mathrm{C}\left(\mathrm{g} / \mathrm{cm}^{3}\right)$ & 0.7313 & 0.7412 \\
Total sulfur (wt\%) & 0.0754 & 0.1878 \\
Mercaptan sulfur (ppm wt) & 193 & 405 \\
TAN (mg KOH/g) & 0.026 & $<0.01$ \\
\hline
\end{tabular}

significantly during the placement of the coupons. Thus, a systematic selection of controlled testing conditions with real condensate or crude oil feedstock for interpreting their corrosivity under practical ranges of operating conditions is missing in literature.

Sulfur-containing compounds in crude oil or condensate feedstock can be of various types like mercaptans, sulfides, disulfides, thiophenes, dibenzothiophenes and benzonaphthothiophenes. It has been reported that mercaptans are the most prominent sources of hydrocarbon feedstock corrosivity due to their relatively easier tendency to dissociate and release $\mathrm{H}_{2} \mathrm{~S}$. Sulfides and disulfides have also been reported as sulfur-containing organic components contributing to $\mathrm{H}_{2} \mathrm{~S}$ generation, under refinery operating conditions $[7,25,37,38]$. Some limited studies have been reported in open literature with respect to dissociation tendencies of various model sulfur-containing compounds under thermal processing in laboratory conditions [31, 34, 38]. It is worth noting that the reactive sulfur-containing compounds are hydroconvertible during hydroprocessing operations; however during prior separation operations e.g. crude/condensate distillation operations, contribute to pipeline and equipment corrosion. de Jong et al. [20] compared the corrosivities of different boiling fractions in an overall range of $275-350{ }^{\circ} \mathrm{C}$, of a crude oil (North Sea origin) as a condensate (Middle East origin) with known mercaptans concentration in each fraction. They found that while corrosivity of different fractions is not related to their mercaptan concentrations, mercaptans of higher molecular weight were more corrosive than the lighter ones. Overall, it would therefore be informative to test different condensate or crude oil feedstock under similar ranges of controlled operating conditions to investigate the dissociative tendencies of their sulfur-containing species contributing to formation of $\mathrm{H}_{2} \mathrm{~S}$.

Refineries often take advantage of availability of opportunity crude and condensate feedstock to process in the feed distillation unit to enhance refinery profit margins. However, first-hand information of detailed sulfur component distributions in the feedstock and hence an expected corrosivity pattern under different processing conditions is usually lacking. Furthermore, no direct and accurate correlations of total sulfur or total mercaptans content in the feedstock to the feedstock corrosivity are available in literature. The current work reports $\mathrm{H}_{2} \mathrm{~S}$ generation patterns from processing two different condensate feedstock, selected due to significantly different corrosive natures, under several operating parameters, as indicators of the corrosivity expected in a condensate distillation section of the refinery. Results clearly highlight the importance of knowing not 


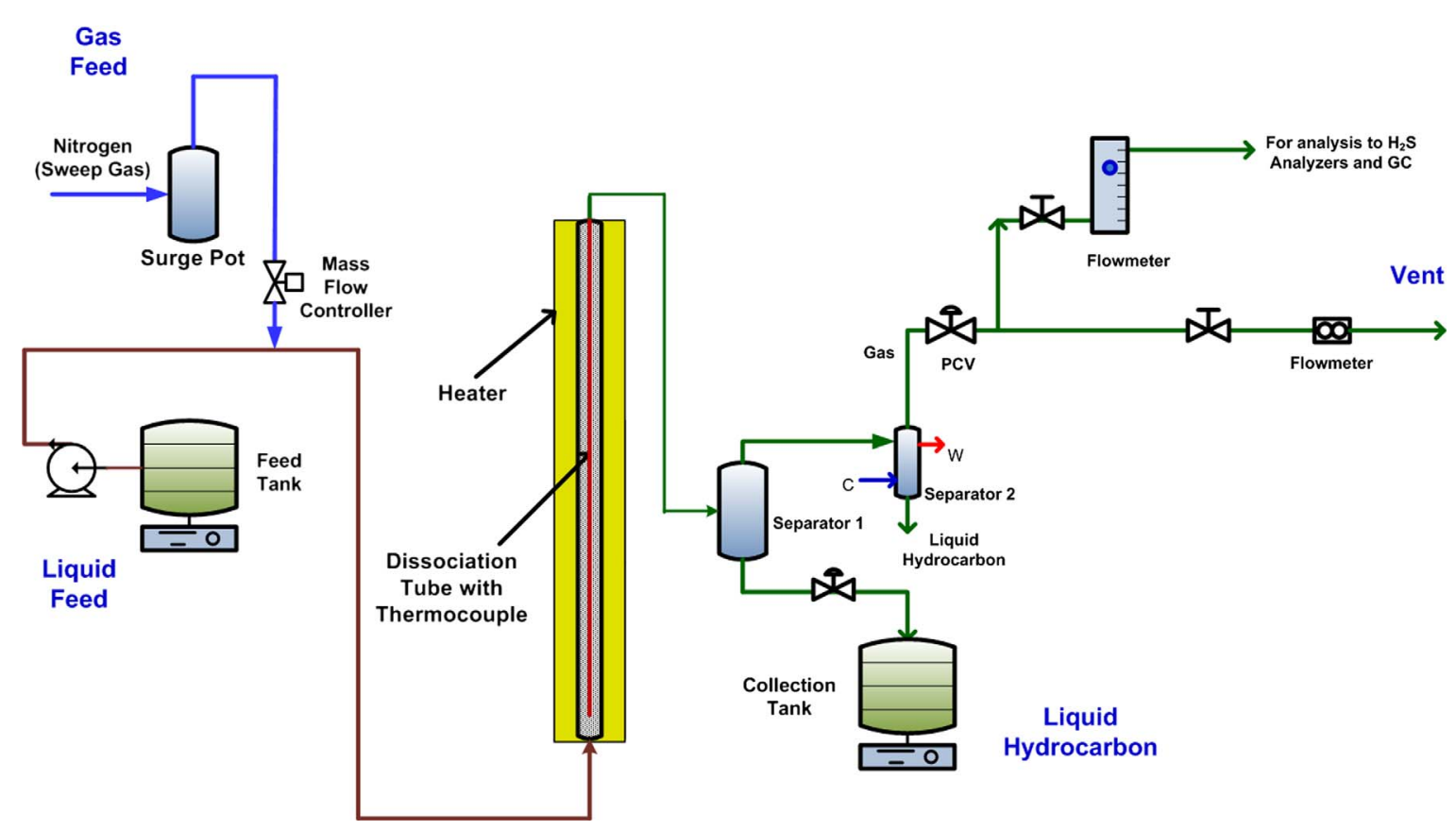

Fig. 2. Pilot plant schematic for studying dissociation of sulfur-containing species in refinery feedstock.

only the total sulfur or total mercaptans content in the feedstock as the fundamental requirement, but the distribution of the different types of sulfur-containing compounds as well.

\section{Experimental setup}

Two refinery feedstock samples from different sources, codenamed as TR1 and TR2 condensates, were chosen for executing the experiments, since they had been reported to exhibit different degrees of corrosiveness in the refinery condensate distillation units. The properties of these feedstock were estimated using standard test methods, as listed in Table 2.

The pilot plant setup consists of feed preparation, dissociation, separation and product analysis sections, as depicted schematically in Figure 2.

Feed preparation section: The liquid feedstock is weighed using a balance with \pm 1 g accuracy. It is preheated to $100{ }^{\circ} \mathrm{C}$ before mixing with nitrogen in the preheating zone. Nitrogen gas, on the other hand, is metered using a calibrated mass flow controller and also preheated to $100{ }^{\circ} \mathrm{C}$.

Dissociation section: The feed is introduced in a co-current upflow mode at the bottom of the isothermal dissociation tube (I.D. $=18.9 \mathrm{~mm}$ ) that is packed up to a height of $780 \mathrm{~mm}$ with ceramic balls having an average diameter of $3 \mathrm{~mm}$. The packing is used to ensure that the flow is evenly distributed along the dissociation zone.

The dissociation tube temperature is maintained at the desired level with $\pm 0.5^{\circ} \mathrm{C}$ accuracy using precisely controlled electric heater blocks. Process fluid temperature inside the heated tube is monitored by three thermocouples located at the top, middle and bottom of the dissociation zone. Pressure is controlled via a back pressure regulator located downstream of the knock-out drum.

Separation section: The dissociation tube effluent is sent immediately to the separator, whose temperature is maintained at $-5{ }^{\circ} \mathrm{C}$. The liquid portion is collected in the product vessel to be weighed while the gas is sent to a knock-out drum (also at $-5{ }^{\circ} \mathrm{C}$ chilled using a mixture of water and ethylene glycol in the ratio of 40:60 in case any liquid might have been carried over).

Product analysis section: The liquid product is analyzed in the laboratory for total sulfur and mercaptans sulfur at the end of each experiment. To achieve accurate total material balance as well as proper sulfur component balance, the setup is configured adequately for the analysis of the gas product. A pressure control valve in the off-gas line controls the system pressure, while the gas volumetric flow rate is metered using a wet gas meter.

$\mathrm{H}_{2} \mathrm{~S}$ evolution was monitored and quantified by online (i) $\mathrm{H}_{2} \mathrm{~S}$ analyzer (LAND Lancom Series-4) as well as (ii) a portable $\mathrm{H}_{2} \mathrm{~S}$ analyzer (OMA 206P UV-Vis Model $A A I$ solutions) that were installed in the off-gas line. An online Gas Chromatograph Refinery Gas Analyzer (GC-RGA) was used to determine gas composition and the molecular weight of the off-gas which was required to check the total as well as the sulfur component material balances. Intermittent gas samples were also collected in gas bags for $\mathrm{H}_{2} \mathrm{~S}$ and sulfur analysis. As mentioned above in the feed preparation section, metered amounts of nitrogen have been fed along with the condensate feedstock. Some minimum flow of a gas stream was necessary to maintain positive flow of the $\mathrm{H}_{2} \mathrm{~S}$ generated by thermal dissociation 
of the sulfur-containing compounds to the analysis instruments. Hence, an inert gas stream of nitrogen was continuously introduced to facilitate quantification of $\mathrm{H}_{2} \mathrm{~S}$ generated. As a control measure to understand implication of introducing nitrogen, two different flow rates of nitrogen were used for the study. This nitrogen gas has been referred to as sweep gas henceforth.

Total sulfur content of the liquid samples collected after each experiment were analyzed by the ASTM D4294 method using ED XRF analyzer. Total amount of mercaptans, on the other hand, are determined using ASTM D3227 method using automatic potentiometric titrator.

For each set of experiments with the two different condensates, codenamed as TR1 and TR2, temperatures were varied from 100 to $400{ }^{\circ} \mathrm{C}$, pressures from 1 to $4 \mathrm{~kg} / \mathrm{cm}^{2} \mathrm{~g}$, sweep gas at two different feed rates (12 and $26.5 \mathrm{NL} / \mathrm{h}$ ), and condensate feed rate varied between 100 and $300 \mathrm{~mL} / \mathrm{h}$. The temperature and pressure ranges were chosen to cover the typical operating conditions in a condensate processing unit in refineries, as described earlier.

\section{Results and discussion}

Since the absolute values of the rate of $\mathrm{H}_{2} \mathrm{~S}$ evolved during each experiment depends on the operating conditions, proper comparison of the results calls for normalization of each. $\mathrm{H}_{2} \mathrm{~S}$ yield at each operating condition has been defined as below:

$$
\begin{aligned}
& \mathrm{H}_{2} \mathrm{~S} \text { yield per feed rate }[\mathrm{mg} / \mathrm{kg}] \\
& =\frac{\mathrm{H}_{2} \mathrm{~S} \text { flow rate in the gas }[\mathrm{mg} / \mathrm{h}]}{\text { Liquid feed flow rate }[\mathrm{kg} / \mathrm{h}]} .
\end{aligned}
$$

This could also be interpreted as the concentration (ppmw) of generated $\mathrm{H}_{2} \mathrm{~S}$, available in a hot confined feedstock stream prior to its removal by any kind of separation technique. For the experimental results in the following sections, the $\mathrm{H}_{2} \mathrm{~S}$ yields have been plotted against different operating variables.

\subsection{Combined effect of temperature and pressure}

Figure 3a depicts the variation of $\mathrm{H}_{2} \mathrm{~S}$ yields with temperature and pressure during processing of condensate TR1. While heating up from room temperature, $\mathrm{H}_{2} \mathrm{~S}$ is detected starting at temperatures as low as $75{ }^{\circ} \mathrm{C}$. Significant amounts of $\mathrm{H}_{2} \mathrm{~S}$ start appearing at $100{ }^{\circ} \mathrm{C}$. This is completely in line with the findings of [27, 28]. Another interesting observation is that at any given temperature, increasing the pressure decreases the rate of $\mathrm{H}_{2} \mathrm{~S}$ generation.

Figure $3 \mathrm{~b}$ shows the variation of $\mathrm{H}_{2} \mathrm{~S}$ yields for thermal treatment of condensate TR2 with variations in temperature and pressure. As a significant observation for $T R 2, \mathrm{H}_{2} \mathrm{~S}$ generation is almost negligible till temperatures of $250{ }^{\circ} \mathrm{C}$, becoming only significant above $300{ }^{\circ} \mathrm{C}$. However, at higher temperatures, e.g. at $400{ }^{\circ} \mathrm{C}$, significantly higher $\mathrm{H}_{2} \mathrm{~S}$ yields, compared to TR1, are registered. Figure $3 \mathrm{~b}$
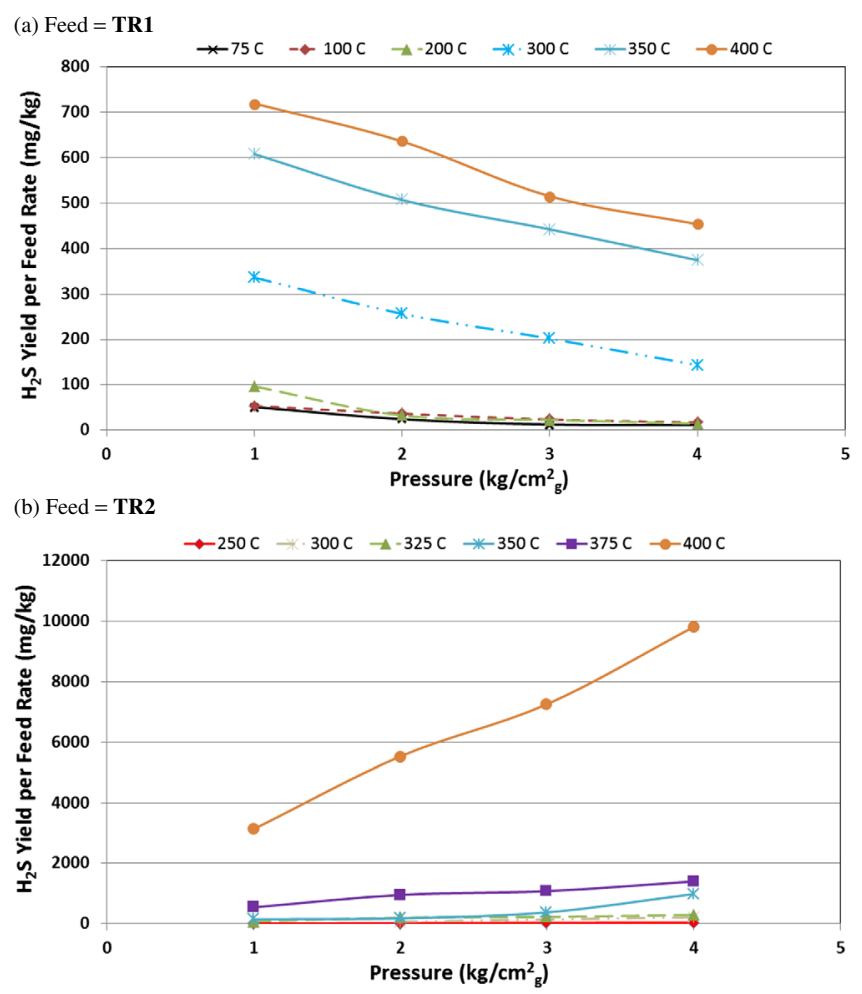

Fig. 3. (a) and (b) $\mathrm{H}_{2} \mathrm{~S}$ yields for varying dissociation temperature and pressure (feed flow rate $=300 \mathrm{~mL} / \mathrm{h}$, sweep gas flow rate $=12 \mathrm{NL} / \mathrm{h})$.

further depicts that at any given temperature for TR2, higher pressures also register higher rates of $\mathrm{H}_{2} \mathrm{~S}$ generation.

For both TR1 and TR2, the common and obvious observation is that at any given pressure, increasing the temperature increases the $\mathrm{H}_{2} \mathrm{~S}$ yields. This suggests an Arrhenius-type kinetically controlled reaction mechanism of sulfur species dissociation into $\mathrm{H}_{2} \mathrm{~S}$. Some researchers have attributed the sulfur compound dissociation merely to the boiling points of these components [20]. This could indicate that the dissociation reactions occur primarily and predominantly in the vapor phase of the mixture, and hence the concentration of the dissociation-prone sulfur-containing species in the vapor phase is important. In other words, higher $\mathrm{H}_{2} \mathrm{~S}$ generation at higher temperatures could also be contributed to by the increased availability of the sulfur components in the gas phase due to enhanced vaporization at higher temperatures.

Interestingly however, for any given temperature, the trends of $\mathrm{H}_{2} \mathrm{~S}$ generation with changing pressures have been found to be clearly opposite for increasing system pressure for the two condensates tested, with TR1 exhibiting increased $\mathrm{H}_{2} \mathrm{~S}$ formation while TR2 registering decrease in $\mathrm{H}_{2} \mathrm{~S}$ formation. In general, increasing the system pressure increases the partial pressure of the dissociation-prone sulfur-containing compound, which would then usually enhance the rate of dissociation reaction, leading to higher rates of $\mathrm{H}_{2} \mathrm{~S}$ generation. Increasing the system pressure, however, also could potentially condense some amounts of sulfur-containing compounds back into the liquid phase, making these components less available for dissociation 


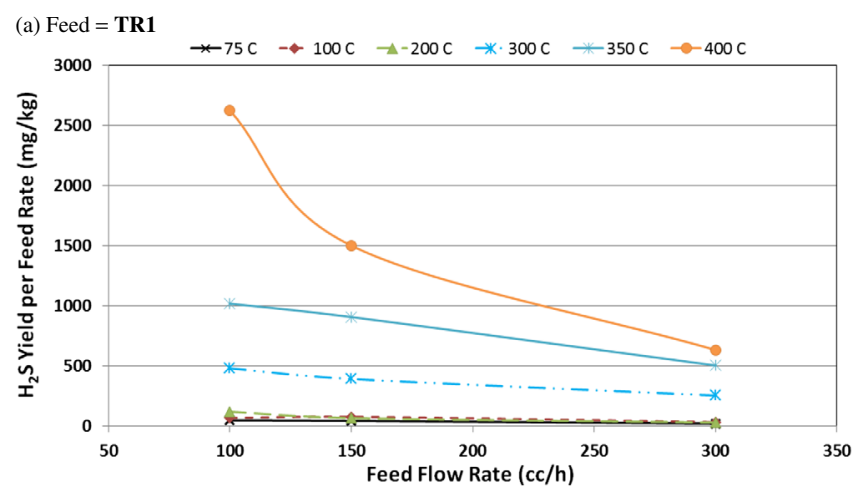

(b) Feed $=\mathbf{T R 2}$

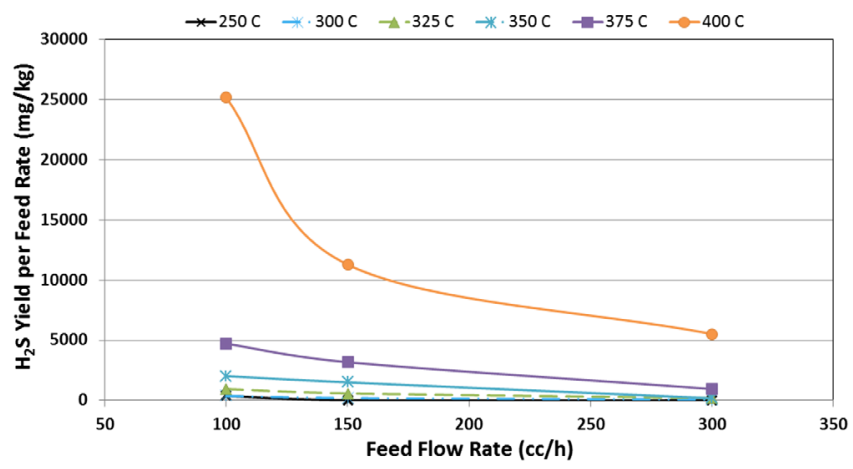

Fig. 4. (a) and (b) $\mathrm{H}_{2} \mathrm{~S}$ yields for varying dissociation temperature and feed flow rate (Pressure $=2 \mathrm{~kg} / \mathrm{cm}^{2} \mathrm{~g}$, sweep gas flow rate $=12 \mathrm{NL} / \mathrm{h})$.

reactions. Hence the distribution of these individual species (once key components are identified) in the vapor and liquid phases for different operating conditions need to be estimated using vapor liquid equilibrium calculations. Furthermore, it is important to consider that there can be wide variations among the dissociative tendencies of different types of sulfur-containing compounds, as well as among the species of each type.

The net dissociation rate is likely to be culmination of availability of the individual sulfur-containing species in the vapor phase compounded with temperature and system pressure, and hence this will be dependent on the detailed sulfur component distribution for the two condensates. A future dedicated study to identify key sulfur-containing components of each type (i.e. mercaptans, sulfides, etc.) and utilize selected model mercaptans and sulfides among these in a suitable base like synthetic oil would be able to identify the interplay of these two temperature-dependent phenomena and their relative contributions to generation of $\mathrm{H}_{2} \mathrm{~S}$.

\subsection{Effect of feed flow rate}

Variation of $\mathrm{H}_{2} \mathrm{~S}$ yields with liquid feed flow rates are given in Figure 4a for condensate TR1 and in Figure 4b for condensate TR2. For increasing feed rates of each condensate, $\mathrm{H}_{2} \mathrm{~S}$ yields have been observed to decrease, which is due to the increasing space velocities or decreasing residence times within the dissociation tube. This further substantiates that the dissociation of the sulfur-containing components to generate $\mathrm{H}_{2} \mathrm{~S}$ is kinetically controlled, for the

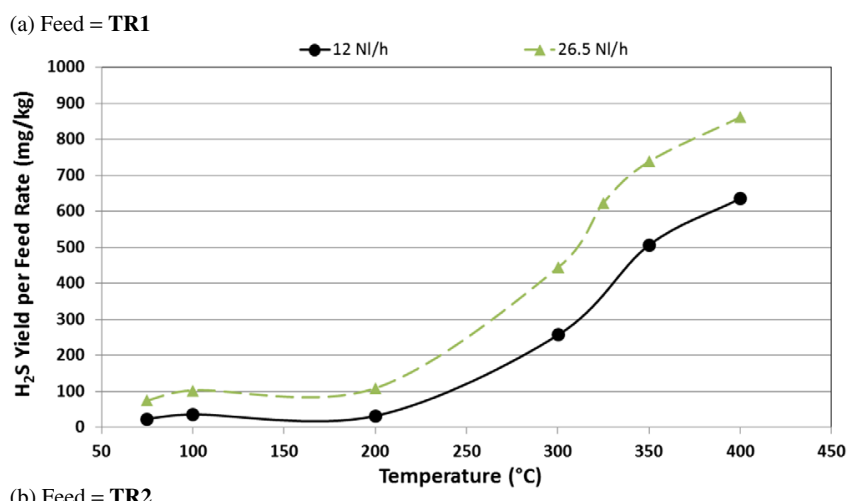

(b) Feed $=\mathbf{T R 2}$

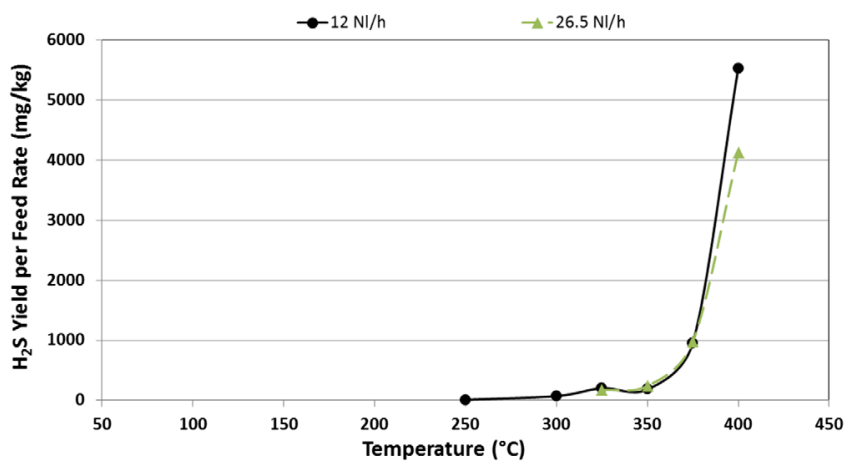

Fig. 5. (a) and (b) $\mathrm{H}_{2} \mathrm{~S}$ yields for varying dissociation temperature and sweep gas flow rate (feed flow rate $=300 \mathrm{~mL} / \mathrm{h}$, Pressure $=2 \mathrm{~kg} / \mathrm{cm}^{2} \mathrm{~g}$ ).

range of operating conditions tested. This also indicates that in the condensate processing units, $\mathrm{H}_{2} \mathrm{~S}$ concentrations in the condensate streams in pipelines would generally be higher for longer lengths at elevated temperatures.

\subsection{Effect of sweep gas flow rate}

As mentioned earlier, sweep gas $\left(\mathrm{N}_{2}\right.$, in the present experiments) is required to drive the generated $\mathrm{H}_{2} \mathrm{~S}$ as part of the product gas stream, in order to be able to accurately quantify the $\mathrm{H}_{2} \mathrm{~S}$ generation by dissociation of sulfur-containing species. However, it is to be noted that the change of the sweep gas flow rate effectively alters the concentration of any sulfur-containing species, and hence its partial pressure, in the product gas stream. Directionally, increasing the sweep gas flow rate as well as decreasing the total pressure both lead to decreasing the partial pressure of the sulfurcontaining components in the vapor phase. On top of that, the species can further distribute between the liquid and vapor phases depending on the vapor-liquid equilibrium of the mixture, as discussed earlier.

This is precisely the observation while subjecting the condensate processing to two different sweep gas flow rates. As depicted in Figure 5a for TR1, higher sweep gas flow rate (i.e. potentially lower partial pressure of sulfurcontaining species in vapor phase) increases the generation of $\mathrm{H}_{2} \mathrm{~S}$. This is in agreement to observation depicted in Figure $3 \mathrm{~b}$, whereby lower total pressure (i.e. potentially lower partial pressure of sulfur-containing species in vapor phase) registered higher yields of $\mathrm{H}_{2} \mathrm{~S}$ generation. This is 

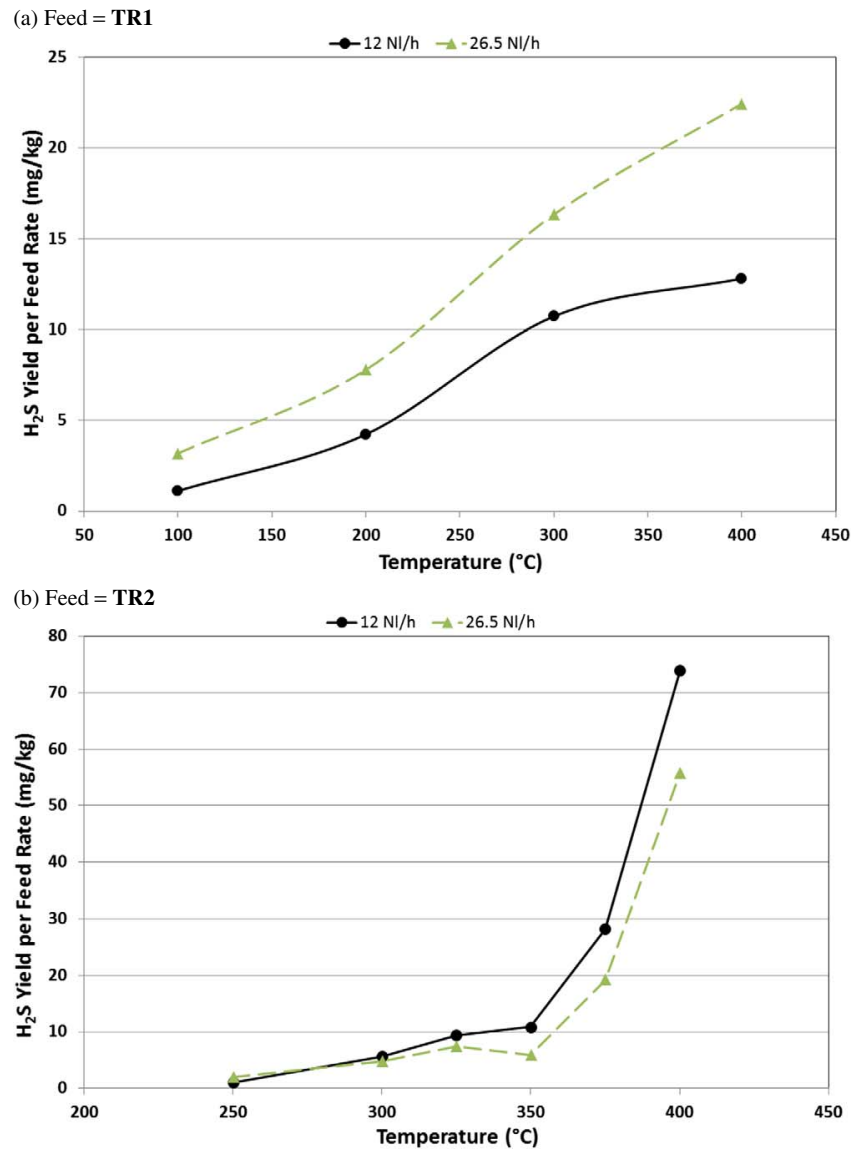

Fig. 6. (a) and (b) $\mathrm{H}_{2} \mathrm{~S}$ yields for varying dissociation temperature and sweep gas flow rate (feed flow rate $=100 \mathrm{~mL} / \mathrm{h}$, Pressure $\left.=0.3 \mathrm{~kg} / \mathrm{cm}^{2} \mathrm{~g}\right)$.

contrary to the understanding that higher concentration of sulfur-containing species in the vapor phase should result to higher rates of dissociation and hence enhance $\mathrm{H}_{2} \mathrm{~S}$ generation. As pointed out earlier, increasing the system pressure also could potentially condense some sulfurcontaining compounds back into the liquid phase (thereby actually decreasing the species partial pressures), making these components less available for dissociation reactions.

In contrast, as depicted in Figure 5b for TR2, decrease in sweep gas flow rate replicates the effect of higher system pressure, as depicted in Figure $3 \mathrm{~b}$.

Clearly therefore, the observations from Figures $3 \mathrm{a}, 3 \mathrm{~b}$, $5 \mathrm{a}$ and $5 \mathrm{~b}$ for the two condensates are consistent, but warrants further detailed analysis of the individual sulfurcontaining species or their types in these condensates, followed by thermodynamic analysis of their distribution in the two phases at specific operating scenarios. Such detailed analysis, however, is not in the scope of this study.

Figures $6 \mathrm{a}$ and $6 \mathrm{~b}$ have been included to demonstrate results similar to those in Figures $5 \mathrm{a}$ and $5 \mathrm{~b}$ at a different combination of condensate feed flow rates and system pressure, further testifying that the grossly opposing trends of $\mathrm{H}_{2} \mathrm{~S}$ yields at varying sweep gas rates for the two condensates are very much in line with the observed opposing trends for varying system pressure for any given temperature.

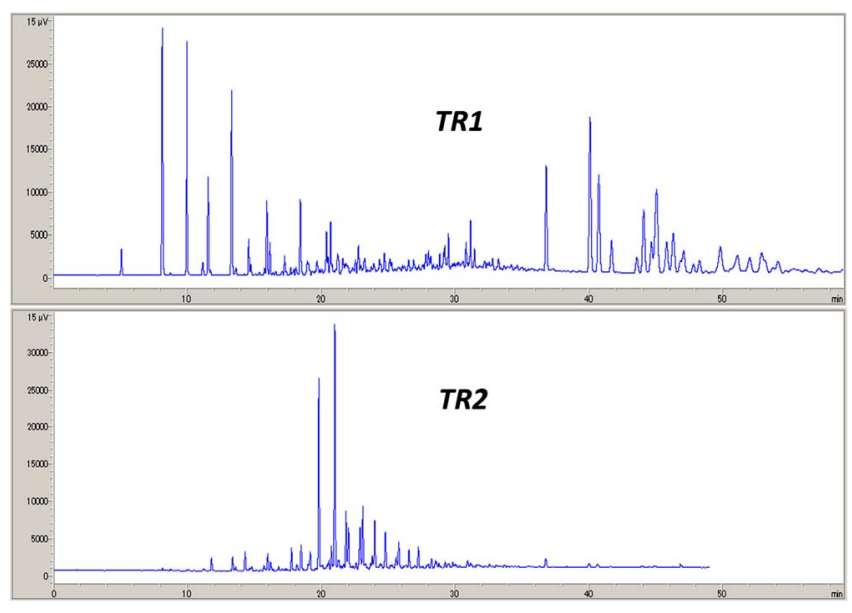

Fig. 7. Sulfur species distribution in whole condensates.

The mercaptans content as well as the total sulfur content of condensate $T R 2$ is roughly twice that in the condensate TR1. However, this gross quantification of mercaptans and the total sulfur contents do not reflect proportionally in $\mathrm{H}_{2} \mathrm{~S}$ generation tendencies of these two condensates at various operating conditions, as depicted in Figures 3-6. Hence it is very important to investigate the distribution of these sulfurous compounds to get better insights of the compound types which are responsible for $\mathrm{H}_{2} \mathrm{~S}$ generation, and their compositions in the condensates.

Figure 7 depicts the distribution of the sulfur species using GC-SCD. It is evident that the patterns of the sulfur-containing components in the two condensates against the retention time, which are in close correspondence to the boiling point of these species, are very different. The sulfur component peaks for $T R 2$ were more concentrated towards the middle of the chromatogram, while they were widely distributed, even towards the two ends of the chromatogram for TR1.

A proprietary technique, description of which is not in the scope of this work, developed and executed by Idemitsu Kosan Co., utilized sequential $\mathrm{AgNO}_{3}$ extraction steps to separate the different types of sulfur-containing compounds in the whole condensate samples, into highly distinct mercaptans, sulfides and combined disulfides and thiophenes groups. Figure 8 depicts the distribution of the different types of the sulfur-containing species after further analysis using GC-SCD technique. Figures $8 \mathrm{a}-8 \mathrm{c}$ represent the distribution of mercaptans, sulfides and the disulfides \& thiophenes respectively. It is generally understood $[9,20,21]$ that the $\mathrm{H}_{2} \mathrm{~S}$ formation is mostly contributed to by the more active components like the mercaptans and the sulfides. Figure $8 \mathrm{a}$ demonstrates that TR1 has higher amounts of lighter mercaptans compared to TR2, and hence $\mathrm{H}_{2} \mathrm{~S}$ generation starts at much lower temperatures in case of TR1. Figures $8 \mathrm{~b}$ and $8 \mathrm{c}$ also clearly demonstrate the highly significant differences of sulfurcontaining components in the two different condensate feedstock, in terms of sulfides, disulfides and thiophenes as well. However, in order to explain the macroscopic trends 

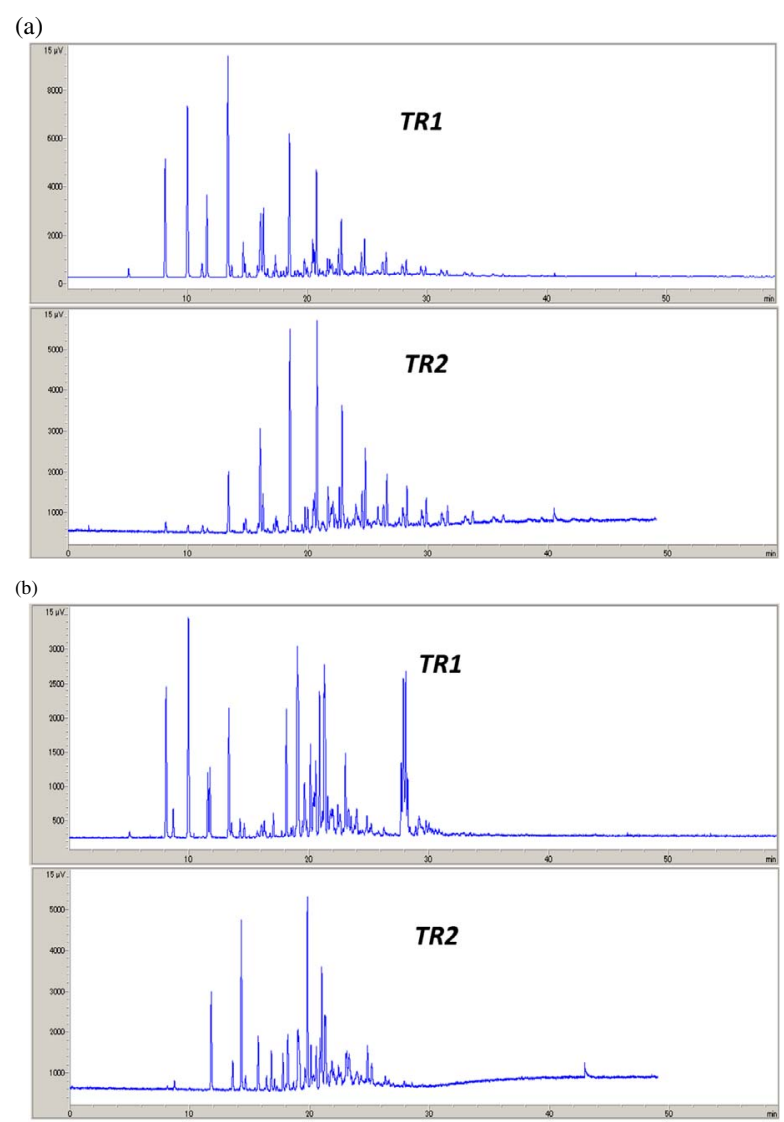

(c)

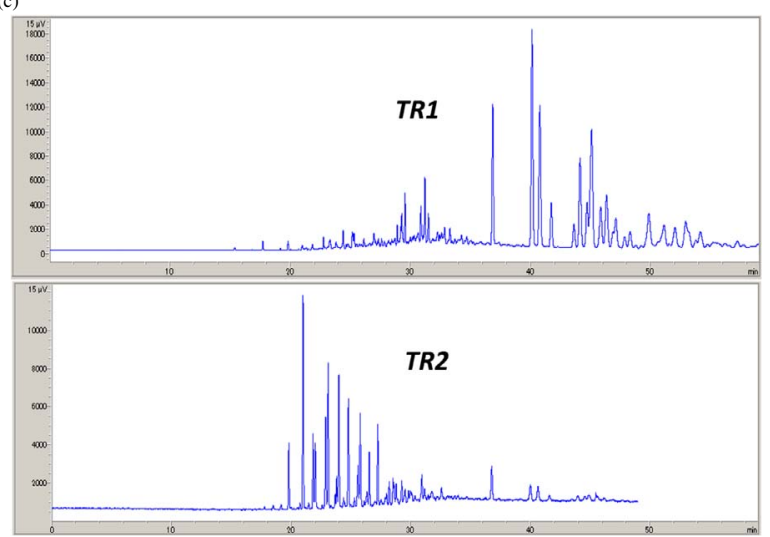

Fig. 8. (a) Mercaptans distribution in the whole condensates. (b) Sulfides distribution in the whole condensates. (c) Disulfides and thiophenes distribution in the whole condensates.

in terms of $\mathrm{H}_{2} \mathrm{~S}$ generation, detailed speciations of the sulfur-containing compounds are required.

\section{Conclusion}

Two condensate feedstock, codenamed as TR1 and TR2, were processed in a pilot plant to mimic the range of operating conditions, which is likely to be encountered in condensate processing in a refinery. Temperature was varied from 100 to $400{ }^{\circ} \mathrm{C}$, while pressure was varied from 1 to
$4 \mathrm{~kg} / \mathrm{cm}^{2}$ g. $\mathrm{H}_{2} \mathrm{~S}$ generation rates during the test conditions were related to the condensate feed rate for each test condition, and values were reported as yields. As expected, higher temperatures and higher residence time in the heated zone enhance rates of $\mathrm{H}_{2} \mathrm{~S}$ generation. This indicates kinetic dependence of the underlying dissociation reactions. For TR1, a higher pressure was observed to have a negative impact on the $\mathrm{H}_{2} \mathrm{~S}$ generation for processing the condensate, whereas this had a positive impact for TR2. This could be attributed to the vapor fraction in the process fluid at different pressures at any given temperature, since the dissociation of sulfur-containing components could be taking place predominantly in the vapor phase. This is further corroborated by the experimental data sets with variations of the nitrogen sweep gas. Higher sweep gas has the same effect as lower experimental pressure, both of which in general should effectively decrease the concentration of the sulfur-containing species in the gas phase. However, this does not clearly explain the grossly different behavior of TR1 and TR2 for changes in pressure or sweep gas flow rates.

GC-SCD analysis of the whole condensate as well as chemically separated types of sulfur components demonstrates that concentrations of the individual sulfurcontaining compounds are drastically different in the two condensates. In fact, the distributions of the different types (e.g. mercaptans, sulfides, etc.) of sulfur-containing compounds were found to be conspicuously different for the two condensates. Thus, the component type distribution among the sulfur species has been found to have a significant impact on the pattern of $\mathrm{H}_{2} \mathrm{~S}$ generation as a function of processing conditions of a refinery condensate distillation unit. Hence, it is not only the total sulfur content or total mercaptans content in the condensate feedstock which dictates $\mathrm{H}_{2} \mathrm{~S}$ production trend during thermal treatment of these feedstock. Rather, it is the distribution of thermally more active type of sulfur species, like the mercaptans, which impacts more the $\mathrm{H}_{2} \mathrm{~S}$ generation, and its associated corrosive nature in refining operations. It is therefore extremely important to evaluate the pattern of $\mathrm{H}_{2} \mathrm{~S}$ generation under different operating conditions, mainly of temperature and pressure in the condensate processing section of a refinery to understand the potential corrosive impacts to different regions in the condensate distillation unit circuit. However, since it is not always practical for refineries to conduct such comprehensive kinetics experiments for different condensate or crude feedstock, it would be very useful for refineries to have detailed sulfur component analysis for the candidate opportunity feedstock for potential utilization.

Acknowledgments. The authors gratefully acknowledge $A D N O C$ Refining and $A D N O C$ Refining Research Centre management for their support, and the support of Idemitsu Kosan Company in conducting analysis of sulfur containing species for the two condensate feedstock.

\section{References}

1 Chevron Assay Library, $H / C A M S, V .10 .0$, Haverly Systems, Inc. 
2 Speight J.G. (2014) Oil and gas corrosion prevention: from surface facilities to refineries, 7th edn, Gulf Professional Publishing, Massachusetts, USA/Oxford, UK.

3 Groysman A. (2017) Corrosion problems and solutions in oil refining and petrochemical industry, 1st edn, Springer, Switzerland.

4 Groysman A. (2017) Corrosion problems and solutions in oil, gas, refining and petrochemical industry, Koroze Ochr. Mater. 61, 3, 100-117.

5 Lefebvre X., Pasquier D., Gonzalez S., Epsztein T., Chirat M., Demanze F. (2015) Development of reactive barrier polymers against corrosion for the oil and gas industry: From formulation to qualification through the development of predictive multiphysics modeling, Oil Gas Sci. Technol. Rev. IFP Energies nouvelles 70, 2, 291-303.

6 Bhowmik P.K., Hossain M.E., Shamim J.A. (2012) Corrosion and its control in crude oil refining process, 6th International Mechanical Engineering \& 14 th Conference Annual Paper Meet (6IMECE14APM), Dhaka, Bangladesh.

7 Piehl R.L. (1960) Correlation of corrosion in a crude distillation unit with chemistry of the crudes, Corrosion 16, 6, 305-307.

8 Hucinska J. (2003) Influence of sulphur on high temperature degradation of steel structures in the refinery industry, $A d v$. Mat. Sci. 3, 1.

9 White R.A., Ehmke E.F. (1991) Materials selection for refineries and associated facilities, National Association of Corrosion Engineers, Houston, TX, USA.

10 Jin P., Nesic S., Wolf H.A. (2015) Analysis of corrosion scales formed on steel at high temperatures in hydrocarbons containing model naphthenic acids and sulfur compounds, Surf. Interface Anal. 47, 4, 454-465.

11 Kane R.D., Cayard M.S. (2002) A comprehensive study on naphthenic acid corrosion, in: Corrosion, NACE, Houston, TX, USA.

12 Qu D.R., Zheng Y.G., Jiang X., Ke W. (2007) Correlation between the corrosivity of naphthenic acids and their chemical structures, Anti-Corros. Methods Mater. 54, 4, 211-218.

13 Xin Q., Dettman H.D. (2016) Corrosivity study of sulfur compounds and naphthenic acids under refinery conditions, in: Corrosion, NACE, Vancouver, Canada.

14 Qu D.R., Zheng Y.G., Jing H.M., Yao Z.M., Ke W. (2006) High Temperature Naphthenic Acid Corrosion and Sulphidic Corrosion of Q235 and $5 \mathrm{Cr} 1 / 2 \mathrm{Mo}$ Steels in Synthetic Refining Media, Corr. Sci. 48, 1960-1985.

15 Dettman H.D., Li N., Wickramsinghe D., Xu Z., Chen X.N., Elliott G.R.D. (2012) The influence of naphthenic acid and sulfur compound structure on global crude corrosivity under vacuum distillation conditions, in: Corrosion, NACE, Salt Lake City, UT, USA.

16 Huang B.S., Yin W.F., Sang D.H., Jiang Z.Y. (2012) Synergy effect of naphthenic acid corrosion and sulfur corrosion in crude oil distillation unit, Appl. Surf. Sci. 259, 664-670.

17 Jin P., Robbins W., Bota G. (2018) Effect of sulfur compounds on formation of protective scales in naphthenic acid corrosion in non-turbulent flow, Corr. Sci. 131, 223-234.

18 Yépez O. (2005) Influence of different sulfur compounds on corrosion due to naphthenic acid, Fuel 84, 97-104.

19 Timmins P.F. (1996) Predictive corrosion and failure control in process operations: as applied to the refining, petrochemical, and process industries, The Materials Information Society, Materials Park, OH, USA.

20 de Jong J.P., Downling N., Sargent M., Etheridge A., Saunders-Tack A., Fort W. (2007) Effect of mercaptans and other organic sulfur species on high temperature corrosion in crude and condensate distillation units, in: Corrosion, NACE International, Nashville, TN, USA.

21 Baker K.C. (2001) Prediction tools for sulfidic corrosion, Mater. Perform. 40, 62-65.

22 Jayaraman A., Saxena R.C. (1995) Corrosion and its Control in Petroleum Refineries - a Review, Corr. Prev. Control 42, 123-131.

23 Hua R., Wang J., Kong H., Liu J., Lu X., Xu G. (2004) Analysis of sulfur-containing compounds in crude oils by comprehensive two-dimensional gas chromatography with sulfur chemiluminescence detection, J. Sep. Sci. 27, 691-698.

24 Lobodin V.V., Robbins W.K., Lu J., Rodgers R.P. (2015) Separation and characterization of reactive and non-reactive sulfur in petroleum and its fractions, Energy Fuels 29, 10, 6177-6186.

25 Couper A.S. (1963) High temperature mercaptan corrosion of steels, Corrosion 19, 11, 396-401.

26 Faragher W.F., Morrell J.C., Comay S. (1928) Thermal decomposition of organic sulfur compounds, Ind. Eng. Chem. 20, 5, 527-532.

27 Suleiman M.I. (2015) Sulphur species corrosivity in refinery feed stock, Solid State Phenom. 227, 213-216.

28 Suleiman M.I., Chandak N.R., Maqtari A.A. (2015) Innovative corrosion testing using a fully automatic fixed bed pilot plant unit, EuroCorr, Graz, Austria.

29 Jin P., Robbins W.K., Bota G. (2017) Effect of temperature on scale formation in high-temperature corrosion by model naphthenic acids and sulfur compounds under replenishing conditions, Energy Fuels 31, 9, 10222-10232.

30 Jin P., Nesic S., Wolf H.A. (2014) Analysis of corrosion scales formed on steel at high temperatures in hydrocarbons containing model naphthenic acids and sulfur compounds, Corrosion, San Antonio, TX, USA, NACE.

31 Patrick W.N. (1952) Investigation of the thermal decomposition of methyl and ethyl disulphides, Thesis, University of British Columbia, Vancouver, Canada.

32 Thompson C.J., Meyer R.A., Ball J.S. (1952) Thermal decomposition of sulfur compounds. I. 2-Methyl-2-propanethiol, J. Am. Chem. Soc. 74, 13, 3284-3287.

33 Thompson C.J., Meyer R.A., Ball J.S. (1952) Thermal Decomposition of Sulfur Compounds. II. 1-Pentanethiol, J. Am. Chem. Soc. 74, 13, 3287-3289.

34 Sehon A.H., Darwent B.D. (1954) The thermal decomposition of mercaptans, J. Am. Chem. Soc. 76, 19, 4806-4810.

35 Olsson T. (2012) Evaluation of corrosion in different parts of an oil refinery using corrosion coupons, Thesis, Chalmers University, Sweden.

36 Farrell D., Roberts L. (2010) A Study of high temperature sulfidation under actual process conditions, in: Corrosion, NACE, San Antonio, TX, USA.

37 Coleman H.J., Thompson C.J., Rall H.T., Smith H.M. (1953) Thermal stability of high-sulfur crude oils, Ind. Eng. Chem. 45, 12, 2706-2710.

38 Yang B., Tian S., Zhao S. (2006) A study of thermal decomposition of alkanethiols in pressure reactor Fuel Process. Technol. 87, 673-678. 